- Notes -

\title{
Separation, Purification and Bioactivity of Broccolini Leaves Flavonoids
}

\author{
Bingfang WANG and Xuewu ZHANG* \\ College of Light Industry and Food Sciences, South China University of Technology, Guangzhou, China \\ *To whom correspondence should be addressed: Dr XW Zhang, College of Light Industry and Food Sciences, South China \\ University of Technology, 381 Wushan Road, Guangzhou 510640, China. \\ (Received September 15,2011; Accepted November 2,2011)
}

\begin{abstract}
Broccolini (Brassica oleracea Italica $\times$ Alboglabra) is a hybrid of broccoli and Chinese kale. To date, no information is available on the separation and purification of flavonoids in broccolini (not broccoli). The objectives of this work were the separation and purification of broccolini leaves flavonoids using solvent extraction and polyamide resin chromatography. By this method, three purified fractions (BLF1, BLF2 and BLF3) were obtained and the flavonoids content of the purified products increased from $10.2 \%$ to $41.6 \%$. HPLC and LC-MS/MS analyses indicated that BLF1 primarily consisted of quercetin (content up to 85.4), BLF2 was primarily composed of kaempferol (content up to $78.5 \%$ ), and BLF3 contained two major constituents kaempferol and apigenin (contents up to $82.6 \%$ ). Furthermore, the anti-cancer activity of the extract before and after purification was compared using a human colon cancer cell line SW480. The results showed that the crude extract BLF0 and the purified extracts (BLF1, BLF2 and BLF3) all exhibited an inhibitory effect on the growth of SW480 cells, and the IC50 values were estimated to be 88.14, 65.06, 72.62 and $79.42 \mu \mathrm{g} / \mathrm{mL}$, respectively, i.e. the anti-cancer activities on SW480 cells were increased by $10-26$ $\%$ after purification.
\end{abstract}

\section{Introduction}

Flavonoids are a large group of naturally occurring phenolic compounds ubiquitously distributed across the plant kingdom, and have many positive impacts on human health including antioxidation, anti-inflammatory, and anti-cancer properties, prevention of atherosclerosis and anti-microbial activity [1]. Flavonoids can be obtained by different extraction and separation techniques, such as liquid-liquid extraction and column chromatographic procedures including silica gel, Sephadex, polyamide, macroporous resin, etc. [2,3]. In order for a successful investigation of bioactive plant constituents, it is important to perform efficient separation and fast identification of the chemical constituents. HPLC is the most widely used technique for the separation of complex mixtures of polyphenolic compounds in plant extracts [4,5]. Recently, the application of LC-MS to the analysis of flavonoids in plants has increased with the advent of "soff" ionization techniques such as electrospray ionization (ESI) [6-9]. ESI generates mainly protonated and deprotonated ions from relatively small plant metabolites like flavonoids [10]. LC-ESI-MS/MS has proved to be a powerful tool for the rapid chracterization and identification of the chemical constituents [11]. 
Broccolini (Brassica oleracea Italica $\times$ Alboglabra) is a green vegetable similar to broccoli but with small florets and long, thin stalks. It is sweeter than broccoli and the delicate stalks do not need to be peeled. Although often misidentified as young broccoli, it is a cross between broccoli and kailan (Chinese broccoli, Chinese kale or Cabbage mustard). It is also called baby broccoli or asparation. Nutritionally, broccolini is high in some active ingredients such as vitamins (A, C), folate, flavonoids and gluosinolates.

To date, no information is available on the separation and purification of flavonoids in hybrid broccolini (not broccoli). The objectives of this work were: (1) the separation and purification of flavonoids from the leaves of broccolini using a polyamide resin-based column chromatography approach, (2) the identification of the flavonoids from broccolini leaves using a high-performance liquid chromatography method coupled with electrospray ionization mass spectrometry (HPLC-ESI-MS/MS), and (3) the anti-cancer activities of various fractions in human colon cancer cells using MTT assay.

\section{Experimental}

\subsection{Materials and chemicals}

Broccolini was bought from Guangzhou Research Institute of Vegetables (Guangzhou, China). The dried leaf was ground in a cutting mill to pass through an 80-mesh sieve to obtain fine powder, which was stored in a sealed container for further use. Rutin and quercetin were purchased from Sigma Chemicals Co. Other chemicals were purchased from China National Medicine Group Shanghai Corporation (Shanghai, China). All chemicals and solvents used were of analytical grade.

\subsection{Extraction of broccolini leaves flavonoids}

Flavonoids were extracted from the dried leaf powder samples (2000 g) by ultrasonic-assistance under the designed conditions: ethanol concentration $70 \%$, solid to liquid ratio 1:30 (w/v, ethanol), ultrasonic power $180 \mathrm{~W}(25 \mathrm{~Hz})$, water bath temperature $60^{\circ} \mathrm{C}$ and extraction time $60 \mathrm{~min}$. The crude extract was filtered and kept for further use.

\subsection{Determination of total flavonoids}

The total flavonoids content in the extracts was determined using a colorimetric method $\left(\mathrm{NaNO}_{2}-\mathrm{Al}\left(\mathrm{NO}_{3}\right)_{3}-\mathrm{NaOH}\right.$ system) with minor modification [12]. Preparation of a standard curve: $0,0.5,1.0,1.5,2.0$ and $2.5 \mathrm{~mL}$ of rutin standard solution $(0.2 \mathrm{mg} / \mathrm{mL})$ were added into separate volumetric flasks $(10 \mathrm{~mL})$. Sodium nitrite $(0.3 \mathrm{~mL}, 5 \%)$ and aluminum nitrate $(0.3 \mathrm{~mL}, 10 \%)$ were added, respectively. After fully mixing and standing for $6 \mathrm{~min}$, sodium hydroxide $(4 \mathrm{~mL}, 4 \%)$ was added. Each flask was finally diluted with ethanol $(60 \%)$ to a defined volume $(10 \mathrm{~mL})$. The absorbance of each flask was examined at $510 \mathrm{~nm}$ with a $1 \mathrm{~mL}$ blank solution for comparison. The regression equation of the rutin standard curve was obtained as $y=0.087 x-0.0005\left(R^{2}=0.9991\right)$, where $y$ is the absorbance, $x$ is the flavonoid content $(\mathrm{mg} / \mathrm{mL})$. Using the same method of standard curve preparation, $1 \mathrm{~mL}$ of prepared sample was used to measure the flavonoids concentration of the crude extract $(\mathrm{mg} / \mathrm{mL})$. The extract was concentrated by evaporation of the ethanol and was dried to constant weight. The flavonoids content was calculated as follows:

Total flavonoids content $(\%)=(C \times V / M) \times 100 \%$

where $C$ is the total flavonoids concentration of the extract solution $(\mathrm{mg} / \mathrm{mL}), V$ is the volume of the extract solution $(\mathrm{mL})$, and $M$ is the mass of total flavonoids after drying (mg).

\subsection{Purification of broccolini leaves flavonoids}

The purification process is summarized in Figure 1. Specifically, the crude extract was vacuum-evaporated to dryness, and the residue obtained was dissolved in $70 \%$ ethanol. Petroleum ether was added to remove impurities like chlorophyll. The petroleum ether layer was concentrated by removing the ethanol. Ethyl acetate $(1 \mathrm{~L})$ was added to the concentrated solution for extraction (three times). The combined ethyl acetate layers were evaporated to dryness under vacuum to obtain 
Fraction A. Subsequently, $n$-butanol $(1 \mathrm{~L})$ was added to the residual solution after ethyl acetate extraction for the extractions (three times). The combined $n$-butanol layers were vacuum-evaporated to dryness to give Fraction $\mathrm{B}$. Then, a column chromatography method based on a polyamide resin (pretreated with $95 \%$ ethanol to remove impurities) was used for further separation of the obtained Fractions A and B. Briefly, the ethanol pretreated polyamide resin was loaded into a glass column $(2.0 \times 30 \mathrm{~cm})$. Samples were dissolved in ethanol with ultrasonic assistance and passed through the column at a rate of $2 \mathrm{BV}$ (bed volume)/h. After standing for $60 \mathrm{~min}$ to allow full adsorption of the flavonoids by the polyamide resin, sample solutions were firstly eluted with distilled water, secondly with $50 \%$ ethanol and finally with $70 \%$ ethanol to generate two major layers. Fractions were collected every $10 \mathrm{~min}$. All collected fractions were then freeze-dried. The sorption and desorption capacities were determined by the following equations [3]:

$$
\begin{aligned}
& Q_{\mathrm{e}}=\left(C_{0}-C_{\mathrm{e}}\right) V_{\mathrm{i}} / W \\
& E=\left(C_{0}-C_{\mathrm{e}}\right) / C_{0} \times 100 \% \\
& D=C_{\mathrm{d}} V_{\mathrm{d}} /\left(\left(C_{0}-C_{\mathrm{e}}\right) V_{\mathrm{i}}\right)
\end{aligned}
$$

where $Q_{\mathrm{e}}$ is the adsorption quantity at equilibrium $(\mathrm{mg} / \mathrm{g}) ; E$ is the adsorption ratio (\%), defined as the percent mass of total adsorbate adsorbed at equilibrium; $D$ is the desorption ratio (\%); $C_{0}$ and $C_{\mathrm{e}}$ are the initial and equilibrium concentrations of solutes in the solutions, respectively $(\mathrm{mg} / \mathrm{mL}) ; V_{\mathrm{i}}$ is the volume of the initial feed solution $(\mathrm{mL}) ; W$ is the weight of the dry adsorbent $(\mathrm{g}) ; C_{\mathrm{d}}$ is the concentration of the solutes in the effluent $(\mathrm{mg} / \mathrm{mL})$; and $V_{\mathrm{d}}$ is the volume of the effluent $(\mathrm{mL})$.

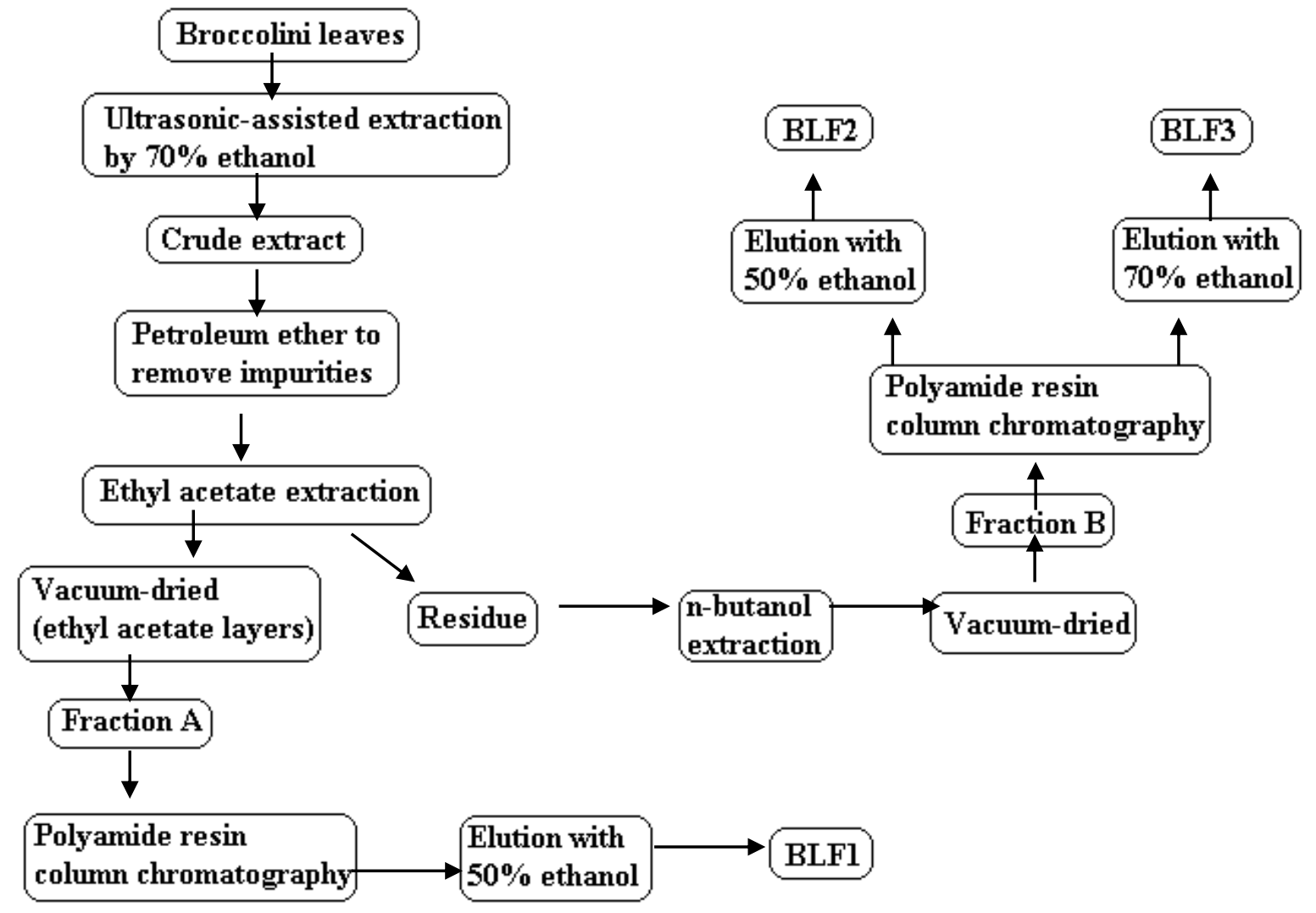

Figure 1. Flowchart for separation and purification of flavonoids from broccolini leaves.

\subsection{HPLC and LC-ESI-MS analyses of broccolini leaves flavonoids}

The crude flavonoids extract $(0.1 \mathrm{mg} / \mathrm{mL}$, dissolved in methanol) was separated using a Waters 1525 system (Waters) with a Waters 2487 tunable absorbance detector and a Waters 717 plus Auto sampler. The mobile phase was composed of 
solvents A (methanol) and B (water with $0.3 \%$ phosphoric acid). Two elution procedures were tested. For gradient elution: $95 \%$ B at the start; changed to $62.5 \%$ B in 10 min; $57.5 \%$ B in 35 min; $45 \%$ B in 60 min; $5 \%$ B in 80 min; $95 \%$ B in 95 min. For equivalent elution: the binary solvent system was fixed at $A / B=60 / 40(v / v)$. The injection volume was $5 \mu \mathrm{L}$. The flow rate was $0.8 \mathrm{~mL} / \mathrm{min}$. The $\mathrm{UV}$ absorption of flavonoids was monitored at $360 \mathrm{~nm}$.

LC analysis was performed using an Agilent 1100 series LC (Agilent, USA) equipped with a diode array detector. Elution with solvent $\mathrm{A}$ (methanol) and solvent $\mathrm{B}$ (water with $0.3 \%$ acetate acid) in a step gradient manner at a flow rate of $0.8 \mathrm{~mL} / \mathrm{min}$ was carried out as follows: $95 \% \mathrm{~B}$ at the start; changed to $62.5 \% \mathrm{~B}$ in $10 \mathrm{~min} ; 57.5 \% \mathrm{~B}$ in $35 \mathrm{~min} ; 45 \% \mathrm{~B}$ in $60 \mathrm{~min} ; 5 \% \mathrm{~B}$ in $80 \mathrm{~min} ; 95 \%$ B in $95 \mathrm{~min}$. The column was at room temperature. The sample injection volume was $5 \mu \mathrm{L}$. The detection was at $365 \mathrm{~nm}$. For identification, MS analysis was performed on a triple quadrupole instrument (Thermo Electron Corporation, USA), equipped with an ESI positive and negative ion source. Samples were dissolved in methanol and infused in the ESI source for detection with ESI+3.0 kV and ESI-2.8 kV. The total ion scanning range was 100-3000 $\mathrm{m} / \mathrm{z}$. Nitrogen was used both as a drying gas and as a nebulising gas at a flow rate of $350 \mathrm{~L} / \mathrm{h}$. The desolvation temperature and ionization temperature were $300{ }^{\circ} \mathrm{C}$ and $100^{\circ} \mathrm{C}$, respectively.

\subsection{Cell culture and MTT assay}

A human colon cancer cell line SW480 was purchased from the Guangdong province peoples hospital (Guangzhou, China). Complete DMEM medium was obtained from GIBCO (Grand Island, NY, USA). For routine maintenance, SW480 cells were cultured in suspension in DMEM medium with $10 \%$ fetal bovine serum (GIBCO) in a water-jacketed 5 $\% \mathrm{CO}_{2}$ incubator at $37^{\circ} \mathrm{C}$ (Forma Scientific, Marietta, $\mathrm{OH}$ ).

Cell growth inhibition was evaluated using a standard colorimetric MTT assay. Briefly, cells in logarithmic growth phase were plated in 96 -well microtitre plates at a density of $3 \times 10^{3} \sim 10^{4}$ cells/ $100 \mu \mathrm{L} /$ well and allowed to incubate for $24 \mathrm{~h}$ at $37^{\circ} \mathrm{C}$ for attachment. Subsequently, the broccolini leaves flavonoids samples were diluted with the complete medium to the desired initial concentration $(15,30,60,80,120,160 \mu \mathrm{g} / \mathrm{mL})$ and then added to the cells in the logarithmic growth phase. A blank was used as a negative control and a quercetin standard was used as positive control. After incubation for another $24 \mathrm{~h}$, the MTT solution (Bornem, Belgium) ( $20 \mu \mathrm{L}$ of $5 \mathrm{mg} / \mathrm{mL}$ ) was added to each well, and incubated for an additional $4 \mathrm{~h}$ at 37 ${ }^{\circ} \mathrm{C}$. The MTT-containing medium was removed and the formazan crystals, formed within the cells, were solubilized by the addition of DMSO (Bornem, Belgium) (150 $\mu \mathrm{L} /$ well) and agitation. The absorbance of the samples and control cultures were read at $490 \mathrm{~nm}$ with a spectrophotometer (Model 550 Microplate Reader). The half inhibition rate IC50 was calculated. Each experiment was in triplicate.

\section{Results and Discussion}

\subsection{Extraction and identification of broccolini leaves flavonoids}

In the present work, the dried leaf powder samples were firstly extracted by ethanol under ultrasonic-assistance to obtain crude extract of flavonoids. In Figure 2, the chromatogram of crude extract from broccolini leaves are presented. 


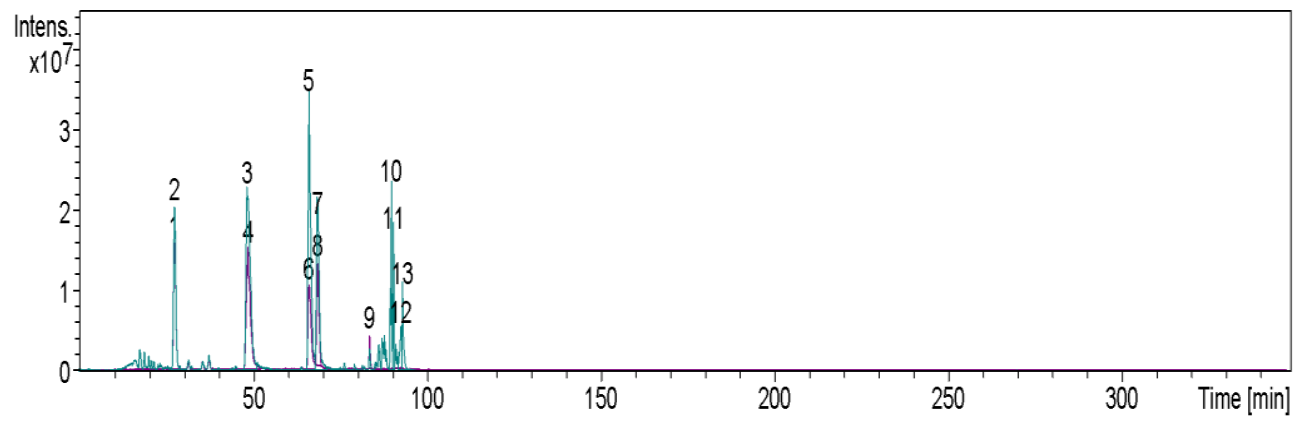

Figure 2. Total ion current (TIC)of the EtOH extract from broccolini leaves.

ESI-MS was frequently used for the detection and identification of compounds in the crude extract from the plants. The identification of each analyte was carried out by comparison of peak retention times, molecular masses, MS/MS fragmentation and the characteristic product ions with those of the available reference standards. The MS and MS/MS spectra in ESI positive and negative mode were particularly good for the detection of both molecular weight and the characteristic fragmentation of the compounds. By comparing retention times with those reported in the literature, no flavonoids compounds are found beyond a retention time of $80 \mathrm{~min}$, so the author ignored peaks 9-12 in Figure 2. The positive ion MS/MS spectra of chromatographic peaks 1-8 for the crude extract from broccolini leaves are shown in Figure 3.

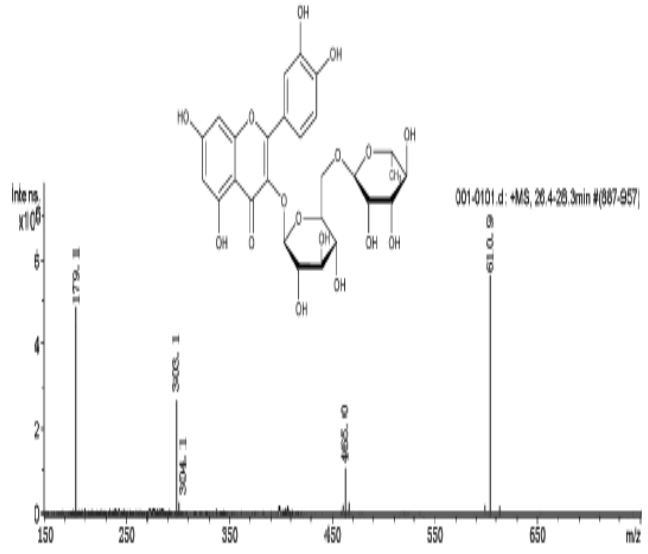

A

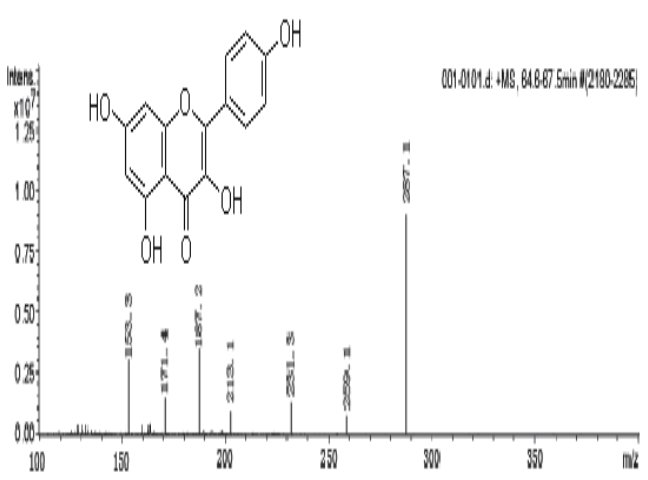

C

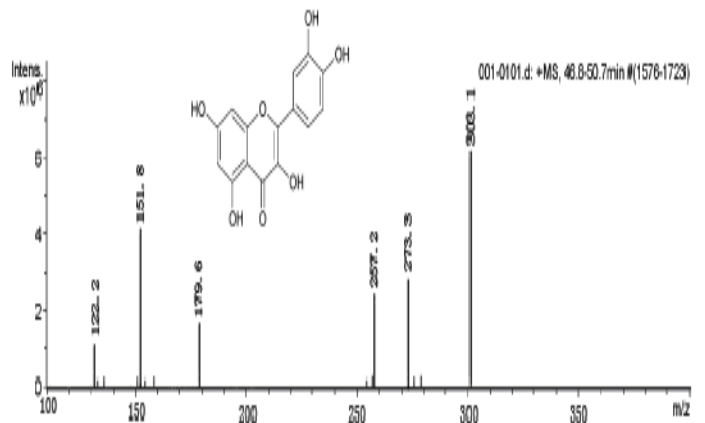

B

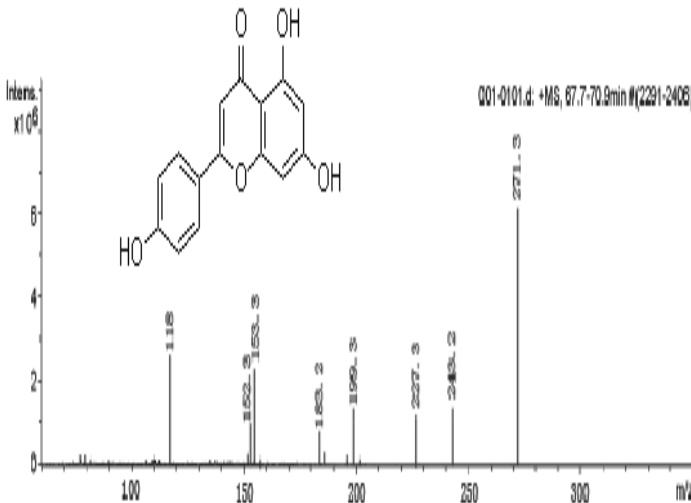

D

Figure 3. The ESI-MS fragments of peaks in Figure 1. (A) Peak 1, (B) Peak 3, (C) Peak 5, (D) Peak 7. 
Chromatographic peaks 1 and 2 with a retention time of $26.4 \mathrm{~min}$ showed an $[\mathrm{M}+\mathrm{H}]^{+}$ion at $610.9 \mathrm{~m} / \mathrm{z}$ and an $[\mathrm{M}-\mathrm{H}]^{-}$ ion at $608.9 \mathrm{~m} / \mathrm{z}$. MS/MS studies (Figure $3 \mathrm{~A}$ ) revealed main fragments at 303.1, 304.1 and $465.0 \mathrm{~m} / \mathrm{z}$. The fragment 465 $\mathrm{m} / \mathrm{z}$ could be attributed to the loss of glycoside 6-deoxy-L-mannose from the parent ion, $\mathrm{m} / \mathrm{z} 303.1$ could indicated the loss of $\beta$ - $D$-glucoside from $465 \mathrm{~m} / \mathrm{z}, 303.1 \mathrm{~m} / \mathrm{z}$ could be quercetin and become $[\mathrm{M}+2 \mathrm{H}]^{+} 304.1 \mathrm{~m} / \mathrm{z}$ after transferrence of hydrogen. The compound was identified as rutin.

Chromatographic peaks 3 and 4 with a retention time of $46.8 \mathrm{~min}$ presented a parent ion of $301.0 \mathrm{~m} / \mathrm{z}$ in negative ion mode and $303.1 \mathrm{~m} / \mathrm{z}$ in positive ion mode (Figure $3 \mathrm{~B}$ ). The fragments observed were: 273, 257, 179, 151 and $122 \mathrm{~m} / \mathrm{z} .273$ $\mathrm{m} / \mathrm{z}$ indicated the loss of $\mathrm{CO}, 257 \mathrm{~m} / \mathrm{z}$ was attributed to the loss of $\mathrm{CO}_{2}, 179 \mathrm{~m} / \mathrm{z}$ could be produced by the breakage of two $\mathrm{C}-2$ bonds and transferrence of two hydrogens, as well as $151 \mathrm{~m} / \mathrm{z}$ resulting from the breakage of two C-3 bonds. These results allowed the identification of quercetin.

Peaks 5 and 6 detected at $64.6 \mathrm{~min}$ are due to a deprotonated molecular ion at $285.1 \mathrm{~m} / \mathrm{z}$ and a protonated molecular ion at $287.2 \mathrm{~m} / \mathrm{z}$ (Figure $3 \mathrm{C}$ ). The second-generation fragmentation ions include: 257.1, 229.1, 211.1, 185.1, 169.1 and 151.1 $\mathrm{m} / \mathrm{z} .257 \mathrm{~m} / \mathrm{z}$ corresponded to the loss of CO. 229 and $211 \mathrm{~m} / \mathrm{z}$ could be result of the loss of CO and HCOOH, respectively. $185 \mathrm{~m} / \mathrm{z}$ was attributed to the loss of $\mathrm{CO}$ and $\mathrm{H}_{2} \mathrm{O}, 169 \mathrm{~m} / \mathrm{z}$ was produced by the loss of $\mathrm{O}$, while $151 \mathrm{~m} / \mathrm{z}$ was generated due to the loss of $\mathrm{H}_{2} \mathrm{O}$. The compound was identified as kaempferol.

Chromatographic peaks 7 and 8 with a retention time of 67.7 min were identified as apigenin, which exhibited an $[\mathrm{M}+\mathrm{H}]^{+}$ion at $271.3 \mathrm{~m} / \mathrm{z}$ and an $[\mathrm{M}-\mathrm{H}]^{-}$ion at $269.2 \mathrm{~m} / \mathrm{z}$ (Figure $3 \mathrm{D}$ ). The second-order fragmentations consisted of: 243.2, $227.3,199.3,183.2,152.2,153.2$ and $118 \mathrm{~m} / \mathrm{z}$. The fragments 243.2 and $227.3 \mathrm{~m} / \mathrm{z}$ were produced due to the loss of $\mathrm{CO}$ and $\mathrm{CO}_{2}$ from parent ion $271.3 \mathrm{~m} / \mathrm{z}$, respectively. Similarly, 199.3 and $183.2 \mathrm{~m} / \mathrm{z}$ were attributed to the loss of $\mathrm{CO}$ and $\mathrm{CO}_{2}$ from $227.4 \mathrm{~m} / \mathrm{z} .152 .2$ and $118 \mathrm{~m} / \mathrm{z}$ could be produced by the breakage of C-ring bonds, and the shift of hydrogen leading to $[\mathrm{M}+2 \mathrm{H}]^{+} 153.2 \mathrm{~m} / \mathrm{z}$.

In general, the breakage of these compounds primarily occurred at 1,2 or 3,4 C-ring bonds ( i.e. clock-wise counted from the top position in the benzene structure), other fragments were formed mainly by rearrangement and the loss of the neutral molecules $\mathrm{CO}$ or $\mathrm{CO}_{2}$, consistent with previous observations [9,13]. The information about retention time, $\mathrm{MS}$ and MS/MS spectra chracteristic of each chromatographic peak, along with the flavonoids identified is presented in Table 1, indicating that the crude extract of broccolini leaves flavonoids contains 4 major constituents: rutin, quercetin, kaempferol and apigenin.

Table 1. The LC-ESI-MS/MS data for analysis of flavonoids in broccolini leaves

\begin{tabular}{|c|c|c|c|c|c|}
\hline \multicolumn{4}{|c|}{ Peak tR/min $[\mathrm{M}+\mathrm{H}]^{+} \mathrm{m} / \mathrm{z}[\mathrm{M}-\mathrm{H}]^{-} \mathrm{m} / \mathrm{z}$} & \multirow{2}{*}{$\begin{array}{l}\text { MS fragments } \\
303.1,304.1,465.0,\end{array}$} & \multirow{2}{*}{$\frac{\text { Identification }}{\text { Rutin }}$} \\
\hline 1,2 & 26.4 & 610.9 & 608.9 & & \\
\hline 3,4 & 46.8 & 303.1 & 301.0 & $273.3,257.2,179.6,151.8,122.2$ & Quercetin \\
\hline 5,6 & 64.6 & 287.2 & 285.1 & 257.1,229.1,211.1,185.1,169.1,151.1 & Kaempferol \\
\hline 7,8 & 67.7 & 271.3 & 269.2 & 243.2,227.3,199.3,183.2,152.2,153.2,118 & Apigenin \\
\hline
\end{tabular}

\subsection{Separation and purification of broccolini leaves flavonoids}

The crude extract of broccolini leaves flavonoids contains many impurities and its flavonoids content was only $10.2 \%$. Subsequently, the crude extract was treated with petroleum ether, and the flavonoids content was increased to $28.4 \%$. Then, ethyl acetate and $n$-butanol were used for further extractions to obtain two extracts, Fraction A and Fraction B, respectively. The flavonoids contents in Fraction A and Fraction B were elevated to $34.3 \%$ and $41.6 \%$, respectively. 
Finally, polyamide resin-based column chromatography was applied for further purification of the extracts. The experiments showed that after adsorption of the flavonoids on the polyamide resin elution firstly with distilled water was very useful to remove impurities, otherwise, the extract was yellow-brown and viscous and contained many polysaccharides and other impurities. In addition, lowing the ethanol concentration had no significant effect on the adsorption of the flavonoids on the polyamide resin and in fact led to obvious tailing and lower desorption efficiency. So, in the present work, $50 \%$ and $70 \%$ ethanol were used for gradient elution. Fraction A was eluted with $50 \%$ ethanol to give a broccolini leaves flavonoids fraction 1 (BLF1). Fraction B was eluted with $50 \%$ and $70 \%$ ethanol to obtain broccolini leaves flavonoids fractions 2 and 3 (BLF2 and BLF3), respectively. The flavonoids contents of BLF1, BLF2 and BLF3 before and after column cromatography are shown in Table 2.

Moreover, the crude extract and adsorption chromatographic fractions were analyzed by HPLC on a Waters liquid chromatographic system. The elution experiments showed that the major components can be well separated both bygradient elution and equivalent elution, but a long time (more than $1 \mathrm{~h}$ ) was required for gradient elution, therefore, equivalent elution $(\mathrm{A} / \mathrm{B}(\mathrm{v} / \mathrm{v})=60 / 40)$ was employed for the crude extract and the purified extracts (BLF1, BLF2 and BLF3) (Figure 4). Based on HPLC chromatograms and the comparison with standards and the results of LC-MS/MS above, the major composition of the three adsorption chromatographic fractions could be determined, BLF1 primarily consisted of quercetin (content up to 85.4) , BLF2 was primarily composed of kaempferol (content up to $78.5 \%$ ), and BLF3 contains two major constituents kaempferol and apigenin (contents up to $82.6 \%$ ). This is partly consistent with previous reports that the predominant flavonoids in broccoli and kale are quercetin and kaempferol [14,15], as broccolini is a cross of broccoli and Chinese kale.

Table 2 The adsorption and desorption results of polyamide resin chromatography on broccolini leaves flavonoids

\begin{tabular}{lccc}
\hline Items & Total solids (g) & Total flavonoids (g) & Flavonoid content (\%) \\
$\begin{array}{l}\text { Fraction A } \\
\text { before on-column }\end{array}$ & 10.0 & 3.43 & 34.3 \\
$\begin{array}{l}\text { Fraction A } \\
\text { after on-column }\end{array}$ & 3.08 & 2.00 & 65.2 \\
$\begin{array}{l}\text { Fraction A elution } \\
\text { with (50\% ethanol) (BLF1) }\end{array}$ & 2.14 & 1.83 & 85.4 \\
\hline Adsorption ratio & $58.3 \%$ & Desorption ratio & $91.5 \%$ \\
\hline $\begin{array}{l}\text { Fraction B } \\
\text { before on-column }\end{array}$ & 10.0 & 4.16 & 41.6 \\
$\begin{array}{l}\text { Fraction B } \\
\text { after on-column }\end{array}$ & 4.34 & & 63.4 \\
$\begin{array}{l}\text { Fraction B elution } \\
\text { with 50\% ethanol (BLF2) }\end{array}$ & 2.05 & 2.75 & 78.5 \\
$\begin{array}{l}\text { Fraction B elution } \\
\text { with 70\% ethanol (BLF3) }\end{array}$ & 1.15 & 1.61 & 82.6 \\
\hline \begin{tabular}{l} 
Adsorption ratio \\
\hline
\end{tabular} & $66.1 \%$ & 0.95 & $93.1 \%$ \\
\hline
\end{tabular}

\subsection{Anti-cancer effects of broccolini leaves flavonoids on human colon cancer cells}

The human colon cancer cell line SW480 was employed to compare anti-cancer effects of the crude extract of 
broccolini leaves flavonoids (BLF0) and the purified extracts (BLF1, BLF2 and BLF3). A blank was used as a negative control and the quercetin standard was used as the positive control. The MTT measurement results showed that broccolini leaves flavonoids (15 160 $\mu \mathrm{g} / \mathrm{mL}$ ) can exert a remarkable inhibitory effect on the growth of SW480 cells. Treating the cells with broccolini leaves flavonoids $(15 \sim 160 \mu \mathrm{g} / \mathrm{mL})$ resulted in a dose-dependent inhibition of cellular proliferation. The IC50 values of BLF0, BLF1, BLF2, BLF3 and positive control quercetin in SW480 cells were estimated to be 88.14, 65.06, 72.62, 79.42 and $54.64 \mu \mathrm{g} / \mathrm{mL}$, respectively. This suggests that the purified extracts exhibit stronger (increased by $10-26 \%$ ) anti-cancer ability in SW480 cells than the crude extract. It has been reported that various mechanisms were involved in the anticancer activity of flavonoids, such as cell cycle arrest [16], apoptosis [17], DNA topoisomerase inhibition [18], mitochondrial dysfunction [19], etc. Different flavonoids possess different antitumor activity. For example, Kanakis et al. [20] reported that the antioxidant activity of flavonoids changes in the order delphinidin > quercetin > kaempferol > morin > naringin > apigenin.. Zhang et al. [21] showed that flavones (luteolin, apigenin, chrysin) and flavonols (quercetin, kaempferol, myricetin) were all able to induce cytotoxicity in the human oesophageal adenocarcinoma cell line (OE33) in a dose- and time-dependent manner, and the cytotoxic potency of these compounds was in the order quercetin > luteolin > chrysin > kaempferol > apigenin > myricetin.. Thus, our present results are consistent with these reports with respect to quercetin, kaempferol, and apigemin.

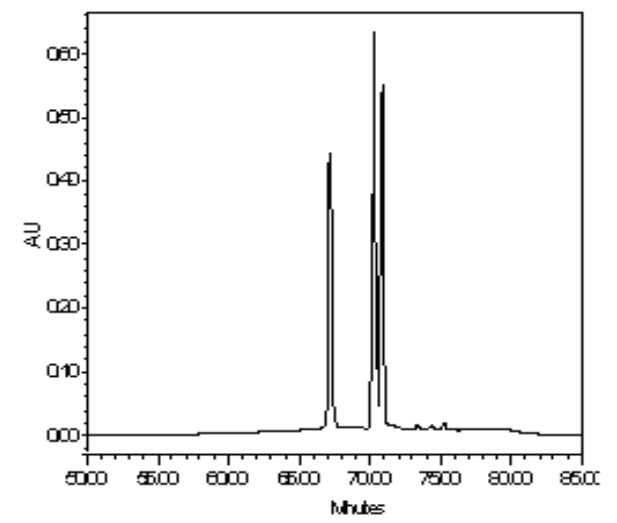

A

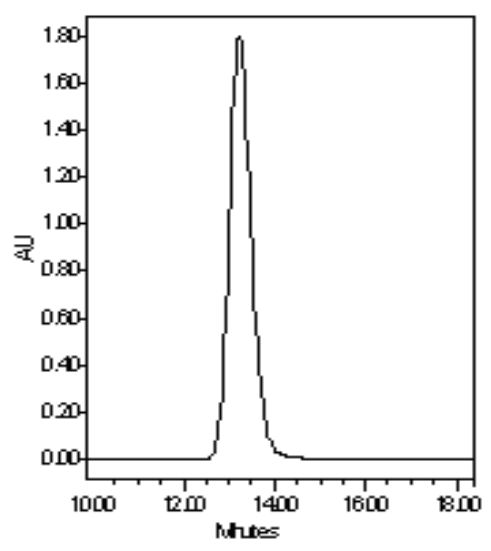

$\mathrm{C}$

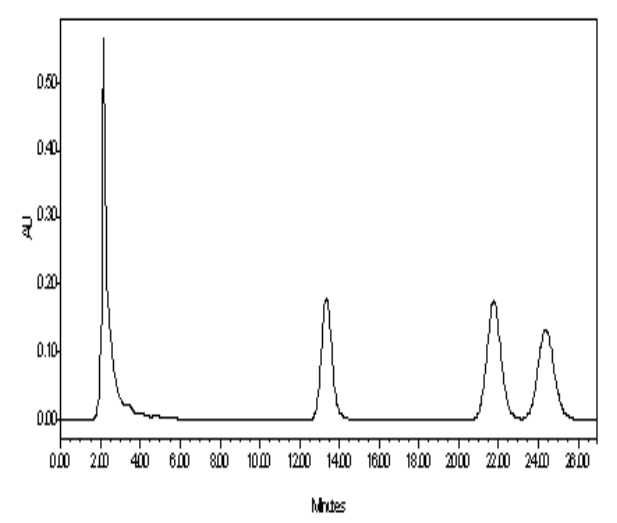

$\mathrm{B}$

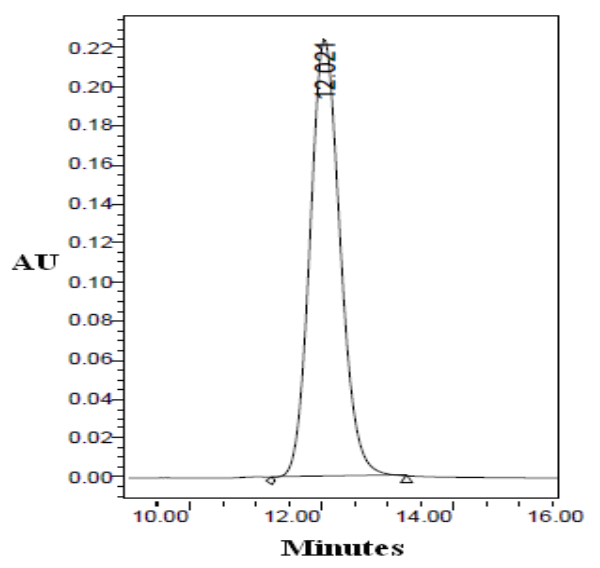

$\mathrm{D}$ 


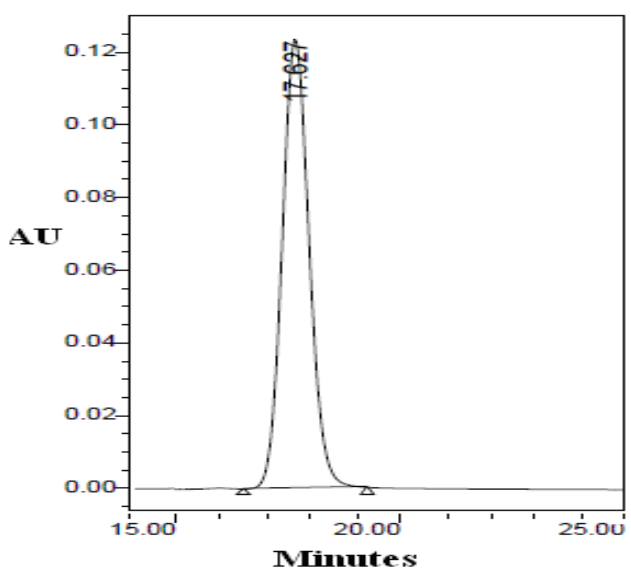

$\mathrm{E}$

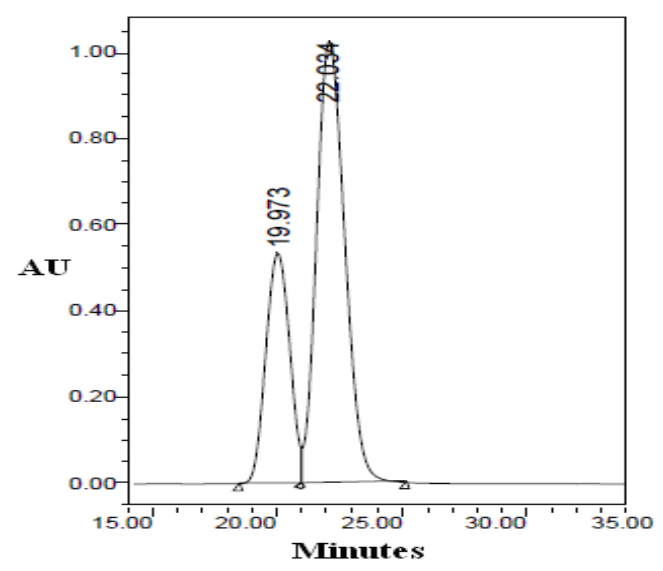

$\mathrm{F}$

Figure 4. HPLC analysis. (A) Gradient elution for crude extract BLF0, (B) Equivalent elution for crude extract BLF0, (C) Quercetin standard, (D) Purified extract BLF1 obtained by elution of the ethyl acetate layer with $50 \%$ ethanol, (E) Purified extract BLF2 obtained by elution of the $n$-butanol layer with $50 \%$ ethanol, (F) Purified extract BLF3 obtained by elution of the n-butanol layer with $70 \%$ ethanol.

\section{Conclusion}

In this study, for the first time, a purification method of flavonoids from broccolini (not broccoli) leaves based on extraction with solvents (petroleum ether, ethyl acetate and n-butanol) and polyamide resin chromatography is reported. With the help of this method, the flavonoids content of the purified products increases from $10.2 \%$ to $41.6 \%$, and three purified fractions (BLF1, BLF2 and BLF3) were obtained. HPLC and LC-MS/MS analysis indicated that BLF1 primarily consisted of quercetin (content up to 85.4), BLF2 was primarily composed of kaempferol (content up to 78.5\%), and BLF3 contains two major constituents kaempferol and apigenin (contents up to $82.6 \%$ ). In addition, bioactivities tests demonstrated that the crude extract BLF0 and the purified extracts (BLF1, BLF2 and BLF3) exhibited anti-cancer activity on human colon cancer SW480 cells, and the IC50 values were estimated to be $88.14,65.06,72.62$ and $79.42 \mu \mathrm{g} / \mathrm{mL}$, respectively, i.e. the anti-cancer activities on human colon cancer cells were increased by $10-26 \%$.

\section{References}

1) Viskupicva J, Ondrejovic M, Sturdik E, Journal of Food and Nutrition Research, 47, 151-162 (2008).

2) Chen JH, Liau BC, Jong TT, Chang CMJ, Separation and Purification Technology, 67, $31-37$ (2009).

3) Jin QZ, Yue JH, Shan L, Tao GJ, Wang XG, Qiu AY, Separation And Purification Technology, 62, 370-375(2008).

4) Rayyan S, Fossen T, Nateland HS, Andersen M, Phytochem Anal , 16, 334-341 (2005).

5) Rodrigues CM, Rinaldo D, Sannomiya M, Dos Santos LC, Montoro P, Piacente S, Pizza C, Vilegasi W, Phytochemical Analysis, 19, 17-24(2008).

6) Exarchou V, Fiamegos YC, van Beek TA, Nanos C, Vervoort J, Journal of Chromatography A, 1112, 293-302 (2006).

7) Lin LZ, Mukhopadhyay S, Robbins RJ, Harnly JM, Journal of Food Composition and Analysis, 20, 361-369 (2007).

8) Ye M, Yan YN, Guo DA, Rapid Communications in Mass Spectrometry, 19, 1469-1484 (2005). 
9) de Moraes SL, Gregorio LE, Tomaz JC, Lopes NP, Chromatographia , 69, 157-165 (2009).

10) Crotti AEM, Vessecchi R, Lopes JLC, Lopes NP, Quimica Nova , 29, 287-292 (2006).

11) Parejo I, Jauregui O, Viladomat F, Bastida J, Codina C, Rapid Communications in Mass Spectrometry, 18, 2801-2810 (2004).

12) Zhang,Y,Li,SF,Wu,XW, Sep.Purif.Technol. , 58,305-310 (2008).

13) Medana C, Carbone F, Aigotti R, Appendino G, Baiocchi C, Phytochemical Analysis, 19, $32-39$ (2008).

14) Zhang JM, Satterfield Mb, Brodbelt JS, Britz SJ, Clevidence B, Novotny JA, Anal.Chem., 75,6401-6407 (2003).

15) KohE, Wimalasiri KMS, Chassy AW, Mitchell AE, Journal of Food Composition and Analysis, 22, 637-643 (2009).

16) Huang HC, Lin CL, Lin JK, Journal of Agricultural and Food Chemistry, 59, 6765-6775 (2011).

17) Sreelatha S, Jeyachitra A, Padma PR, Food and Chemical Toxicology, 49 , 1270-1275 (2011).

18) Bensasson RV, Zoete V, Jossang A, Bodo B, Arimondo PB, Land EJ, Free Radical Biology and Medicine, 51, 1406-1410 (2011).

19) Xie XB, Yin JQ, Jia Q, Wang J, Zou CY, Brewer KJ, Colombo C, Wang YF, Huang G, Shen JN, Oncology Reports, 26, 687-693 (2011).

20) Kanakis CD, Nafisi S, Rajabi M, Shadaloi A, Tarantilis PA, Polissiou MG, Bariyanga J, Tajmir-Riahi HA, Spectroscopy-an International Journal, 23, 29-43 (2009).

21) Zhang Q, Zhao XH, Wang ZJ, Food and Chemical Toxicology, 46, 2042-2053 (2008). 